\title{
Language-in-education policy issues and Karl Marx's views on education
}

\author{
Eureka Mokibelo
}

University of Botswana

\begin{abstract}
This paper examines Botswana Language-in-Education Policy (LiEP) by relating it to the role of education as perceived by Karl Marx's philosophy on ethnic minority groups in primary schools in Botswana. Botswana LiEP still recognizes only two languages of instruction despite the fact that it is a multilingual society with an estimation of 28 languages spoken in the country. The Marxist perspective on education is used as bedrock to describe the relevance of some of its principles and what the policy prescribes in primary school classes through citing some researches. All the cited researches were investigated through a qualitative approach using a questionnaire with open ended questions, interview, class observations, focus groups and field notes. The findings of these studies reveal that there are: inequalities in Primary School classes and beyond, lack of progression to the next levels of education, communication barriers which present themselves in many faces, and poor hostel conditions that impede on learners completion of lower education. This paper has concluded that indeed the capitalist education system imposes its ideology through the LiEP and it presents inequalities amongst learners in classrooms and beyond.
\end{abstract}

Key Words: inequalities, education, Karl Marx's philosophy, ethnic minority learners, Language-ineducation Policy.

\section{INTRODUCTION}

\section{Botswana Language-in-Education Policy}

Botswana language policy has since independence in 1966 been shifting between two languages. It has passed through three phases but it still recognizes only English and Setswana. Before independence, some languages such as Ikalanga were used in the Northern region of Botswana for learning and teaching. After independence the use of indigenous languages for teaching and learning were banned for unity of all ethnic groups. Setswana was recognized as a medium of instruction from Standard One to Standard Three with a shift to English at Standard Four. Then Setswana dominated early learning to unify the nation. In 1977 a task force named the National Commission on Education was appointed to review the education system generally and this task force still gave Setswana a powerful position at early learning and it recommended that Setswana be used as a medium of instruction from Standard One to Standard Four and English from Standard Five. It was argued that learners started using English late at Standard Five despite it being the language of the examinations. Learners were incompetent in using it for examinations and therefore performed poorly (Revised National Policy on Education report, 1993). Another National Commission on Education was appointed in 1993 to review the education system. This commission recommended that at Standard One, Setswana (the national language) be used as a language of instruction while English (the official language) was taught as a subject. The two languages switched positions at Standard Two with English becoming the language of instruction and Setswana being taught as a subject (Revised National Policy on Education, 1994). This is the current policy.

The country has for a long time been falsely seen as monolingual due to the status given to Setswana as a national language (Ramahobo, 2004). The policies have been silent about indigenous languages and this has negatively hampered speakers of such languages, especially in the education system. Not all Batswana speak Setswana as a first language. But Setswana has championed the education system together with English at early learning. The policy excludes ethnic minority groups because it is silent about their indigenous languages in the teaching and learning process. It has already crushed their present, future and it continues to do so. It is close to impossible for learners to learn in two unfamiliar languages taught and used simultaneously and be expected to produce good results. The policy has intensified the division between the dominant and 
the ethnic minority groups. This issue is problematized because masses of learners from ethnic minority groups at primary schools are left out by the education system with a bleak future. It is for this reason that this paper appreciates Karl Marx's position on education.

\section{BACKGROUND INFORMATION}

\section{Languages spoken in Botswana}

There are 29 languages listed in Botswana, and all of which are living languages (Lewis, Simons, \& Fennig, 2013). Setswana is spoken by approximately $80 \%$ of the population as a lingua franca (Nyati - Ramahobo, 2004) while ethnic minority groups learn English as a third, fourth or even fifth language. Research has not established the exact number of languages in the country due to a blurred distinction between a language and a dialect (Batibo \& Smieja, 2000). Setswana as a national language is offered as a compulsory subject at primary and secondary school levels. Like in other countries, language planning and policy and its practical roots in Botswana have been influenced by the colonial era where English was seen as a resourceful language and given prestigious status and indigenous languages being unrecognized.

\section{Research done on Botswana Language-in- Education Policy}

Research has revealed and described in various ways the presumed costs of misleading conclusions that Botswana is monolingual and it has highlighted problems encountered by ethnic minority learners. Four such studies are used as empirical evidence: First, in 2012-2015 a study was conducted on the evaluation of the implementation of the languagein-education policy in six selected rural primary schools - three rural and three urban. The study used qualitative approach with the use of openended questionnaires, interviews, classroom observations and field notes. Some of the findings indicated that the implementation of the languagein-education policy was not adhered to in rural primary schools where ethnic minority groups attended because of the unfamiliar languages of instructions used. Thus, it was difficult for learners to comprehend and understand concepts and it was difficult for learners to communicate with teachers because there was no common language between them. Consequently, learners dropped out of school between 20 - 25 each year at lower primary in Standards One and Two because learners found no reason to sit in classrooms when they could not communicate in the languages used for learning and teaching.

Second, in 2005 - 2006 a study was conducted by Mokibelo, E.B. and Moumakwa, T.V. on the reading problems learners encountered in the learning and teaching processes at Remote Area Dwellers' primary schools. The study used the qualitative approach with the use of open ended questionnaires, interviews, class observations and field notes. The findings indicated that learners were unable to: read, follow written instructions, comprehend texts and answer questions or respond appropriately to texts. Some learners decided to drop out of schools and never completed their lower and upper primary. The dropout rate ranged between 17 - 20 students each year in Standards One and Two.

Third, in 2012 - 2013 another study was conducted by Mokibelo, E.B. to investigate why San learners disengaged from school. The intention of the study was to investigate the issue from the dropouts; hence, the students who dropped out of school were followed in areas where they stayed to get first-hand information. Initially, it was the teachers who speculated on why learners disengaged from school because the learners would not be available to provide reasons for disengaging. The study adopted a qualitative approach and it used an interview and focused groups' methods only. The dropouts revealed that the languages of instruction, especially English, acted as a barrier to communication. Poor hostel conditions and corporal punishment were amongst other things that contributed to the high school dropout. These children never completed primary school and those who did failed.

Lastly, a follow up study was conducted by Mokibelo, E.B. between 2007 - 2008 on hostel life in a Remote Area Dweller primary school. This was a follow up study on learners' reading problems conducted in 2005 - 2006. The study used an interview and hostel inspection methods for data collection. Learners revealed that they found it difficult to read and study in the hostels due to sexual abuse and harassment from older learners and people from the village where the school was located. Learners ended up dropping out of school in Standards One and Two and refused to come back to continue with their education. These learners did not complete their primary education due to harsh conditions at the hostels that went unknown, unmonitored and unsupervised.

Common patterns and trends were observed in the studies cited above. Learners from ethnic minority groups could not express themselves freely due to 
language barrier; learners failed because they were taught in unfamiliar languages - their languages were rejected when they entered the school premises, learners sat for examinations at lower and upper primary although it was obvious that they would fail because they wrote the examinations with unfamiliar languages. Most of the learners dropped out of school because languages of instruction contributed. They found no reason to sit in classrooms while they could not learn. The culture in schools was alien to that of the learners and as a result, they could not relate their lives to it. In this regard, the education system kicked them out at early learning and therefore labelled them as weak and failures even before they could complete their primary education. Learners broke the rules of the education and rejected authority altogether by dropping out of school because there was no sense of belongingness in the capitalist school system.

\section{THEORETICAL FRAMEWORK}

This paper used some of the principles of Karl Marx's as its theoretical framework because they have been found to be relevant to classroom practices that affect ethnic minority groups in the capitalist education system. Karl Marx (1818-1883) was a philosopher whose works inspired communist regimes in the twentieth century. Although he was not an educationist, Karl Marx's writings have influenced education systems worldwide. Some of his writings are still relevant hence, this paper subscribes to Marx's viewpoint on education as regards the languages of instruction. The paper used some of Karl Marx's views that are relevant to the cited researches. Below are the principles that are used and are relevant to this paper. The basic main principles by Karl Marx on education subscribed for are that: education systems reproduce class inequality, legitimate class inequality and they work in favour of the interest of capitalist employers.

In this paper, the principles of reproducing class inequality, and legitimate class inequality underpinned this study because they are appropriate and relevant at primary school level. The two principles "give birth to other babies" such as: education system that benefits the ruling or dominating class; education which is transmitted through a hidden curriculum; cultural capital that benefits middle class learners; and some pupils rebelling which emerged from the researches cited in this paper.

According to Karl Marx, reproducing class inequality in schools means that the elites and middle class use their material and cultural capital to ensure that their children get into the best schools. This means that their children get the best education and then they later occupy middle class jobs while the working class get poorer standard of education and end up in working class jobs. Again, Karl Marx argued that education legitimizes class inequality, meaning that in reality money determines the quality of education that people get. $\mathrm{He}$ also points out that people do not realize that schools spread that children have an equal chance to succeed and that children's grades depend on their effort and ability and yet this is not true. If learners fail we are made to believe that it is their own fault and the system justifies this when in reality it is not learners' fault.

Critical issues observed from these two principles are that: education is not about equal opportunities offered. It has been designed in such a way that it fails ethnic minority groups while the dominant groups succeed; education presents inequalities in classrooms and beyond in societal classes; culture in the classrooms is biased as it is centred on the dominant groups and it presents educational advantages to the dominant groups, hence, the inequality that transcends into the society at large. Again, the examinations are not fair because the dominant class has an economic and cultural advantage over ethnic minority groups and the results are quite predictable. Further, it is difficult for ethnic minority groups to achieve upward mobility in society because the education system "kicks" them out at the initial stages of learning. The education system seems to work towards the interest of the dominant groups only.

This framework challenges Botswana education system to reflect on its language-in-education policy and how it is implemented and observe its relevance to indigenous groups that are part of its citizenry. The theoretical framework finds Botswana education system weak in terms of accommodating all its students' population. Botswana's educational ideologies have been based on the fact that in Botswana all Batswana speak the national language as a first language, hence a monolingual polity. This is rather misleading and has caused disparities and inequalities that are difficult to close and address in a multilingual set up Botswana is. The inequalities caused by languages of instruction have been prevalent for decades and do not seem to being resolved. Although the principles are old and have been criticized, they are real in some cases and some learners lived and experienced them. The theory challenges the education system to consider changing and reshaping its policy and ideologies in a capitalist system. The principles are used as a 
mirror to reflect on capitalist schooling that impose ideologies and transmit only the dominant culture's language, culture and concepts to the subordinate groups.

\section{DISCUSSION}

\section{Languages of instruction: a weapon of destruction}

The findings from all studies cited above indicated that the languages of instruction impede learning and teaching in ethnic minority classes because learners speak different home languages from those of the school. The languages of instruction are unfamiliar (see also Nyati-Ramahobo, 1999; 2004) and they destroy learners' future. Yet, they are supposed to impart basic skills and knowledge to the student population. Production and reproduction is supposed to take place with languages of instruction within the classrooms (Prah, 2005). Therefore, learners struggled with two languages simultaneously that are different from their own in terms of morphology, syntax and concepts. In this regard, the capitalist education system did not give equal opportunities of learning to all the student population. It was the language planning and policy that dictated that there should be only two languages used as languages of instruction despite the fact that other learners do not speak them. It seems the languages of instruction were used as weapons to drive ethnic minority learners from classrooms back to their homes in rural areas where opportunities for progression and development were very minimal.

The capitalist education system did not give learners an opportunity to grow and develop academically because immediately they started schooling they were told that their home languages were not wanted in school. What is important to point out is that, these home languages helped the concerned learners to count, play, express themselves, and tell stories in their day to day interpersonal communication, and they were all of a sudden rendered useless by the capitalist education system. The languages of instruction offered unequal opportunities because learners from ethnic minority groups competed with their fellow pupils using the languages they did not understand. Learners from ethnic minority groups had very little control over their school work. Like Karl Marx (1975) argued, the ethnic minority groups belonged to subordinate classes in society and the languages of instruction created and widened social class gaps right from the classrooms and beyond. The capitalist school system dismissed their independence and creativity in languages they knew and understood. There was minimal knowledge transfer, thus ethnic minority groups' education could not be expanded, cultivated and developed (Prah, 2005). The gaps were widened as other learners from dominant groups progressed academically to the next level of education and entered the world of work because they learned with familiar languages while ethnic minority learners were left trailing behind.

\section{Cultural diversity seen as a problem in the capitalist education system}

Further, the findings indicated that the capitalist education system presented inequalities because the diverse cultures, knowledge and skills learners brought from their homes were neither recognized nor used as background to their education in the capitalist school system. Despite the latter, learners from dominant groups were rendered that opportunity in other parts of the country (see Motshabi, 2006). The ethnic minority groups' cultures, knowledge and skills were crushed and never developed in the capitalist system schools. When we talk about culture we are talking about the people, their thoughts, beliefs, languages and traditions and these cannot be separated from the people. Culture is not only inseparably related to language, but it also plays an important role throughout the process of language teaching and learning (Bentahila \& Davies, 1989). Karl Marx justifies ethnic minority learners' failure by arguing that, it is the consequence of the capitalist school system that reflects the values and cultures of the dominant groups, the subordinate groups are isolated and left out. Prah (2005) in support of Karl Marx's argument, argues that if languages of instruction are different from school languages learners become culturally removed and alienated.

Learners from ethnic minority groups were declared empty containers immediately they started school even though they brought rich cultural background from home (Freire, 1979). In the capitalist school system, there is no system in place to preserve their culture, knowledge and skills because it is more convenient to operate with the dominant culture, knowledge and skills. Like Karl Marx argues, class inequalities that have been observed and have long been systematically arranged through the languages of instruction within the capitalist education system. From the research data, most of the teachers in the education profession were from dominant cultures and bilinguals of Setswana and English, but in some cases, teachers spoke different home languages from Setswana. 
The question that scholars ask is that: if languages of instruction and language policies remain largely bound to the national political context then which agendas are they serving and whose agendas? (Tollefson \& Tsui, 2004). These questions are relevant to a situation where there has been a loud cry of a language policy that is exclusive and that disadvantages others. A situation that emerged from the data, where the background of teachers and learners were different warrants such questions. Teachers' profile did not hold true for ethnic minority learners. Often, teachers stood before their classes, the faces looking back at them did not look like their own, and hence a student was cited saying. "A bunch of teachers here think that they know what's wrong with us. But they don't know. If people want to help us, they have to see what we've been through, not from what their own experiences tell them." - Billie, a Lakota teen speaking of teachers at her high school (Menkart, 2017). The quotation should be food for thought for educational authorities, especially in the capitalist school system. If the capitalist education system is to educate people to transform the society to a more humane and just one, it needs to go through a major reform to include and recognize ethnic minority learners' cultures in the classrooms. As the literature shows, learners' different linguistics and cultures were seen as a problem rather than a resource by the capitalist education system.

\section{Examinations: a sword with two sides}

The findings have also indicated that learners from ethnic minority groups in schools studied failed their Primary School Leaving Examinations dismally due to communication problems while their counterparts elsewhere succeeded. Learners completed their primary education unable to read and write in the languages of instruction. The percentage pass rates in 2012 in three of the studied primary schools ranged between $23-35 \%$. The poor academic performance could not transform ethnic minority learners' lives; instead, the examinations pushed them to the far end. The teachers reported that learners did not understand instructions. They therefore provided wild answers that did not correspond with the questions. The other reasons given for such low grades were that learners were not interested in school, however, such a response is debatable. For example, it will be unreasonable for learners to sit in the four walls of the classroom or learn under a tree daily while they are not benefitting from the teaching and learning process. The examinations results for such primary schools were low and learners were blamed for failing examinations. In the actual fact, the ideological underpinnings of the capitalist school system have been undermined for these unequal opportunities. The big questions raised being that: who was supposed to be educated and pass the examinations? Who had the right to schooling because others were kicked out at early learning by the system (Trueman, 2017)? The possible responses to these questions are that learners who speak the languages of instruction and those who are taught using second language learning approaches are likely to do well. All subjects except Setswana were written in English for all the student population in a democratic polity such as Botswana, but the ethnic minority results in some cases defeated the very purpose for learning.

A closer look at the results and reasons for failure goes back to what Karl Marx said; the capitalist education system is not fair, because only the dominant groups succeed. Learners from ethnic minority groups struggled not only with the languages of instruction but also with concepts in the examinations and assessment. While learners from dominant groups have fewer language problems, ethnic minority learners have language problems as well as a range of socio-economic problems affecting them such as: illiterate parents; staying in hostels away from their parents, parents not assisting with home works, both parents and children not speaking the school languages and poverty. Parents therefore, found it difficult to contribute positively towards their children's education. On the other hand, learners from dominant groups had the languages and cultural capital which they used in the education system to pass the examinations. Like Karl Marx pointed out; this included using sophisticated language skills and broad vocabulary which learners from ethnic minority groups lacked.

It may be reasonable to point out that this study did not assume that all ethnic minority groups studied had been left in the dark by the capitalist education system. There could be some cases where learners from ethnic minority groups beat the odds through the support of local and international organizations and were then having first and second degrees and were even absorbed by the job market. This is a drop in the ocean as compared to the masses left out. More could still be done to support such ethnic minority learners and bring a ray of hope to their lives.

\section{Learners' rejection of the capitalist education system}


Learners rejected the capitalist education system through disengaging from school in significant numbers. The findings indicate that each year close to 20 - 25 learners dropped out of school in Standards One and Two levels. This number is high and it could not be ignored. When the children completed their primary education, half the students enrolled at the beginning of the year would have dropped out. Although parents had shown interest and eagerness in registering their children to attend school, they had been disappointed by the language barrier between their children and teachers and other contributory factors such as cultural differences in capitalist education schools. The expectation is that learners have to obey the school rules and regulations. A good number of reasons that contributed to learners' disengagement from school have been advanced and these include: violence in hostels, corporal punishment, languages of instructions and the culture that is different from theirs (Mokibelo, 2014). The only jobs they would do was become herd-boys since the job does not require formal qualifications in Botswana at the moment. Herding of cattle is done mostly by males, and the females have no option but to stay home. The disengagement from school could be regarded as a situation where learners rejected the capitalist education system because they cannot cope with it.

\section{IMPLICATIONS}

The implications of the capitalist education system are that it declared learners from ethnic minority groups failures at the initial stages of learning as compared to learners from dominant groups, hence widening the social class gap. Also, the capitalist education did not give the student population equal opportunities both in the classrooms and in the examinations, because ethnic minority learners were unable to express themselves in target languages while the dominant groups were able to do so. Further, it could mean that the capitalist education system was interested in learners from the dominant groups only, whether learners from ethnic minority groups had communication problems or not, as long as the dominant groups passed it was deemed okay, since so far no solutions have been provided to address the language barrier problems. Languages of instruction were systematically used to determine who would go for tertiary education and the world of work. These were observations from Karl Marx, his views are relevant and applicable to the current situation in Botswana.

\section{CONCLUSION}

Karl Marx's philosophy on education looms large in our present world - especially Botswana capitalist education system. The inequalities presented by the language-in-education policy have been observed in primary schools and beyond and are still prevalent amongst ethnic minority groups. The inequalities are presented by the language-in-education policy that acts as a two sided sword; one side shows an uphill struggle and the other side controls the power and shows success. The inequalities articulated by Karl Marx are relevant and cannot be ignored. Instead, they keep on increasing recognition amongst academics. His educational perception analysis holds significant for the patterns and trends observed in the teaching and learning processes in the capitalist education system as regards ethnic minority groups in primary schools in Botswana.

\section{REFERENCES}

[1] Bentahila, A., \& Davies, E. ( 1989). Culture and language use: A problem for foreign language teaching. International Review of Applied Linguistic in Language Teaching: 27, 99-112.

[2] Levy, A. (1994). Children's understanding and attitudes about people from other countries. Unpublished master's thesis. University of New Hampshire, Durham.

[3] Lewis, M.P., Simons, G.F., \& Fennig, C.D. (eds.). (2013). Ethnologue: Languages of the World, Seventeenth edition. Dallas, Texas: SIL International.

Online version: http://www.ethnologue.com.

[4] Marx, K., \& Frederick E. (1975-) Collected Works. New York and London: International Publishers and Lawrence \& Wishart (referred in text as $\mathrm{CW}$ with volume number, i.e. CW5).

[5] Mokibelo, E. B. (2014). Why We Drop Out of School: Voices of San School Dropouts in Botswana. The Australian Journal of Indigenous Education: 43 (2) pp. 185-194.

[6] Nyati-Ramahobo, L. (2004). The language situation in Botswana. In Baldauf, R.B., \& Kaplan, R.B. (Eds.). Language Planning and Policy in Africa, Vol. 1: Botswana, Malawi, Mozambique. London: Multilingual Matters.

[7] Republic of Botswana, (2012). Central Statistics Population and Census. Gaborone. Government Printers.

[8] Republic of Botswana, (2016). Vision 2036: Achieving Prosperity for All. Gaborone. Government Printers.

[9] Tollefson, J. W., \& Tsui, A.B.M. (2004). (eds.). Medium of Instruction Policies: Which Agenda? 
Whose Agenda? Mahwah, NJ: Lawrence Erlbaum Associates.

[10]Trueman, C.N. (2017). "Karl Marx and Education" historylearningsite.co.uk, $15^{\text {th }}$ August 2017. 